\title{
Are alexithymia and empathy predicting factors of the resilience of medical residents in France?
}

\author{
Audrey Morice-Ramat ${ }^{1}$, Lionel Goronflot', Gilles Guihard² \\ ${ }^{1}$ Department of General Medicine, Faculty of Medicine, University of Nantes, France \\ ${ }^{2}$ Center for Research in Education of Nantes (CREN), University of Nantes, France \\ Correspondence: Gilles Guihard, Centre de Recherche en Education de Nantes (CREN), EA 2661, Université de Nantes, France \\ Email: gilles.guihard@univ-nantes.fr
}

Accepted: April 05, 2018

\begin{abstract}
Objectives: To explore resilience, resilience predicting factors and resilience distribution in French medical residents.

Methods: A cross-sectional study was conducted in which general practice residents $(n=380)$ were asked to answer the Jefferson Scale of Physician Empathy, the Connor-Davidson Resilience Scale, and the Toronto Alexithymia Scale. One hundred thirty-seven (137) responses were collected. The scores of the different scales have been calculated. The score differences were examined using the Student's t-test or analysis of variance. The correlations were estimated using the Pearson correlation coefficient. The relationships between scores were analysed by multiple linear regression. The heterogeneity of the sample was examined by non-hierarchical cluster analysis.
\end{abstract}

Results: Resilience and empathy were positively correlated $\left(\mathrm{r}_{(135)}=.36, \mathrm{p}<.001\right)$. Alexithymia was negatively correlated with resilience, $r_{(135)}=-.40, \mathrm{p}<.001$, and empathy, $r_{(135)}=-.38, \quad \mathrm{p}<.001$. Resilience was influenced by alexithymia, $\beta=-.284, \mathrm{p}=.001$, empathy, $\beta=.255$, $\mathrm{p}=.002$, gender (female $<$ male), $\beta=-.231, \mathrm{p}=.002$ and year of formation, $\beta=.157, \mathrm{p}=.036$. Two clusters of residents were characterized. They differed by their empathy and resilience profiles and by alexithymia trait.

Conclusions: Alexithymia, empathy, gender and year of formation correspond to predicting factors of resilience. This suggests that the resilience of vulnerable residents can be enhanced by increasing their empathy and by reducing their alexithymia. Thus, teaching teams could sustain their students' well-being through educational programs aiming to develop their understanding of their own emotions and those of their patients.

Keywords: Burnout, coping, family medicine, medical formation, mental health, stress

\section{Introduction}

Professional burnout (PBO) represents an inadequate response to chronic occupational stress. ${ }^{1}$ It results in psychological and physiological consequences that can strongly impact individual well-being, quality of life and job performance. Pathological signs of PBO include cardiovascular and gastrointestinal diseases. ${ }^{2,3}$ PBO is also accompanied by psychological symptoms such as anxiety, depression, motivational decrease, reduced interpersonal commitment and performance limitations. ${ }^{4}$ The PBO prevalence has been estimated in US working adults $(\sim 28 \%),{ }^{5,6}$ in the general population of Sweden $(\sim 13 \%),{ }^{7}$ and Germany $(\sim 4 \%) .{ }^{8}$ A growing body of evidence shows that $\mathrm{PBO}$ affects health care providers, ${ }^{9-11}$ with a prevalence depending upon factors including the geographic location and the specialty of the health profession. ${ }^{12,13}$ Burnout is also reported to impact health students during their training. ${ }^{14-16}$ The prevalence has been determined in different populations of medical students, showing that $\sim 15 \%$ to $\sim 45 \%$ of students are affected. ${ }^{16,17}$ Medical residents are not spared from burnout. In particular, $25 \%$ of general practice residents are impacted by PBO in France. ${ }^{18}$

The resilience represents the ability to show positive psychophysiological outcomes despite experiencing aversive situations or living in a stressful environment. ${ }^{19}$ Improving the resilience of individuals has been evoked to prevent the $\mathrm{PBO}$ occurrence in a broad working context. ${ }^{20}$ Resilience and PBO are characterized by a negative correlation in health professions. ${ }^{21-24}$ Such a correlation is also reported for medical students. ${ }^{25,26}$ Numerous factors influence the resilience of individuals. These include age, gender, cultural environment, living perspectives and personality traits. ${ }^{19,27}$ Alexithymia corresponds to the impaired understanding of one's own emotions. ${ }^{28}$ Alexithymia is observed in patients suffering from psycho-pathological diseases that reduce patient's resilience. ${ }^{29,30}$ Negative correlations between alexithymia and 
resilience have been characterized in Chinese military personnels ${ }^{31}$ and in Iranian students. ${ }^{32}$ Empathy can also represent a factor influencing the resilience. Empathy represents the ability to experience other's emotions and to manifest a cognitive adaptation to promote better interpersonal relationships. ${ }^{33}$ Indirect clues suggest a cross-talk between empathy and resilience. ${ }^{34}$ However, the existence of a significant correlation between empathy and resilience is still discussed. ${ }^{35,36}$

The distribution of resilience among populations was previously assessed by using cluster analysis procedure. Pietrzak and Cook reported the existence of three clusters of individuals with distinct resilience levels among a sample of US veterans. ${ }^{37}$ Doron and colleagues identified five clusters of students differing by their coping strategies in response to stress. ${ }^{38}$ The work of Suriá Martínez indicated the existence of different resilience profiles among a sample of patients with spinal cord injury. ${ }^{39}$ Taken together, these works suggest that the resilience is not distributed according to a single normal distribution. This is also the case for empathy and alexithymia distributions..$^{40,41}$

Although resilience measurement has been described in medical students and in medical residents, ${ }^{25,26,42}$ little is known about the predicting factors of resilience. Furthermore, there is a lack of study concerning the characterization of resilience and resilience predicting factors in French health students. Therefore, the objective of the present study is to explore the resilience of medical students. To do so, a survey was conducted to measure resilience, to determine the nature of predicting factors, and to characterize the distribution of resilience among general practice residents at Nantes University (France). It was hypothesized that: i) the resilience is affected by predicting factors including empathy and alexithymia, and ii) the resilience distribution among a student sample is heterogeneous.

\section{Methods}

\section{Study design and participants}

A cross-sectional study was conducted at Medical School of Nantes University (France). Ethical approval was obtained from the Ethics committee of Nantes University. Project staff was not involved in the diploma allocation. All general practice residents $(n=380)$ were eligible to the study. The return rate was $\sim 40 \%(\mathrm{n}=150)$. Thirteen incomplete answers or with outlying scores (Dixon's test) were discarded. The final sample $(\mathrm{n}=137$, mean age $=26.5, \mathrm{SD}=1.3$ ) corresponded to 94 women (mean age $=26.6, \mathrm{SD}=1.2$ ) and 43 men (mean age $=26.5, \mathrm{SD}=1.6$ ). The proportions of residents registered in years 1, 2 and 3 of the formation corresponded to $\sim 30 \%(\mathrm{n}=$ $41), \sim 39 \%(n=53)$ and $\sim 31 \%(n=43)$. The gender ratio $(F / M)$ differed significantly between years 1 (25/16), 2 (43/10) and $3(26 / 17)\left(\chi^{2}(2, N=137)=6.293, p=.043\right)$. Becoming a general practice resident was a deliberate choice for 123 respondents ( 90\%).

\section{Study tools}

The questionnaire included items related to socio-demographic information (gender, age, year of the curriculum). Items from the French versions of the Jefferson Scale of Physicians Empathy (f-JSPE; 25 items), the Connor-Davidson Resilience Scale (f-CDRISC; 21 items) and the 20-item Toronto Alexithymia Scale (f-TAS20) was also included in our survey. These scales have demonstrated satisfactory reliability for the assessment of resilience, empathy, and alexithymia. ${ }^{43-45}$

The scoring of f-JSPE items is based on a 7-point Likert scale with one corresponding to "full disagreement" and seven corresponding to "full agreement". ${ }^{10}$ items needed reverse scoring because of their formulation. Total f-JSPE score varies from 20 to 140; a high score indicates high empathy. F-CDRISC and f-TAS20 scales use a 5-point Likert scale for item scoring. For f-CDRISC, the item score varies from 0 ("full disagreement") to 4 (for "full agreement"), and the total score varies from 0 to 84 . For f-TAS20, the item score varies from 1 (for "full disagreement") to 5 (for "full agreement"). Five items needed reverse scoring. Total f-TAS20 score varies from 20 to 100 . High scores for f-CDRISC and f-TAS20 indicate high resilience and alexithymia traits.

\section{Data collection procedures}

All general practice residents were contacted by e-mail. They were invited to answer an electronic version of the questionnaire. The access to the questionnaire was granted after the validation of an electronic informed consent in which goals, means, and methods have been described. To ensure resident's anonymity, each resident encoded an identifier by using the first two letters of his/her first name, a number corresponding to the day of birth (between 01 to 31 ), a number corresponding to the year of birth (between 00 and 99), a number corresponding to the place of birth (between 00 and 101) and the first two letters of his/her mother's given name.

\section{Data analysis}

Data were collected at the end of the survey. They were analysed with SPSS 21, Sigma Plot 12 and R (3.2.5) software. FCDRISC scale has recently been validated for resilience measurement in health students. ${ }^{43}$ The reliability of f-JSPE and f-TAS20 scales was re-assessed in our conditions. The item-score correlation coefficient (rIS) was calculated. As Cronbach's a coefficient is not a good estimator of internal consistency for multifactorial scales, ${ }^{46}$ greatest lower bound (GLB) and McDonald's $\omega$ coefficient were calculated as recommended elsewhere. ${ }^{47}$ The scale appropriateness was deduced from the Kaiser-Meyer-Olkin coefficient (KMO, optimal value above .8 ) and the Bartlett's test (optimal $\mathrm{p}<.001$ ). The item-sampling adequacy was deduced from the anti-image correlation coefficient value calculated for each item (AIC, optimal value above .5).

To confirm the 3-factor structure of the f-JSPE and fTAS20 scales, a confirmatory factor analysis (CFA) was 
performed by using the maximum likelihood method. The goodness of fit of a factor model was estimated according to Byrne's recommendations. ${ }^{48}$ The following indices were calculated: i) the normed $\chi^{2}\left(\chi^{2} / \mathrm{df}\right.$, optimal value below 2.0$)$, ii) the standardized root mean square of residuals (sRMR, optimal value below .05), iii) the goodness of fit index (GFI) and the adjusted goodness of fit index (AGFI), both being optimally higher than .90), iv) the root mean square error of approximation (RMSEA, optimal value below .08) and its relative $\mathrm{p}$ (close) for which a value above .05 indicates a good fit, and v) the comparative fit index (CFI) (optimal value above .90).

The normality of data distribution was verified by using the Shapiro-Wilk's test (significance criterion p>.05). Mean (M), standard deviation (SD), 95\% confidence interval (95\% $\mathrm{CI}$ ) and the average score (i.e., the ratio between the total score and the number of items of a scale) were calculated for the different scales and different subgroups. A correlation between two variables was deduced from the value of the Pearson correlation coefficient. The differences were estimated by Student's t-test (for two-group comparison) and by analysis of variance (ANOVA, for multiple-group comparison) in considering a risk $\alpha=.05$. The threshold of significance of a difference was set at $\mathrm{p}<.05$. When a difference was significant, the effect size was estimated by Cohen's $\mathrm{d}$ coefficient (for two-group comparison) with the correction of Rosnow and Rosenthal ${ }^{49}$ or by $\eta^{2}$ coefficient (for multiplegroup comparison). Small, medium and large effect sizes were respectively characterized by $\mathrm{d}, \eta^{2} \leq .2, .2<\mathrm{d}, \eta^{2} \leq .5$ and $.5<\mathrm{d}, \eta^{2} .^{50}$

Multiple linear regression analyses were performed to test whether alexithymia and empathy can predict resilience. Gender (male $=1$, female $=2$ ) and year of formation (year 1 $=1$, year $2=2$ and year $3=3$ ) were also considered as potential predicting factors of resilience. Standardized regression coefficient $(\beta)$ and $\mathrm{p}$ values were calculated to estimate the relationships between the different variables.

The heterogeneity within a dataset can be ascertained by cluster analysis (CA).51 A non-hierarchical CA (K-means) was run by using standardized scores ( $\mathrm{z}$ scores) for f-JSPE, fCDRISC and f-TAS20 as clustering variables. The validity of different models (from 2 to 4 clusters) was assessed. The significance of between-cluster differences was calculated by unpaired Student's t-test (for a 2-cluster model) or by ANOVA and post-hoc Bonferroni correction (for 3- and 4cluster models). The most likely cluster model contained the highest number of clusters for which all $\mathrm{z}$ scores were significantly different. The validity of the retained model was assessed by discriminant analysis (DA), in which $\mathrm{z}$ scores were considered as independent variables, whereas the number of clusters corresponds to the dependent variable. For cluster and discriminant analyses, the significance criterion was set at $\mathrm{p}<.001$.

\section{Results}

The normality of f-JSPE and f-TAS20 scores was confirmed using the Shapiro-Wilk test. Therefore, a factor analysis using maximum likelihood method and an orthogonal rotation (Varimax) could be performed to determine the indicators of reliability, as suggested by Costello and Osborne. ${ }^{52}$ As shown in Table $1, \mathrm{f}$-JSPE and f-TAS20 scales were characterized by acceptable to good appropriateness, item-sampling adequacy, and item-score correlation. The internal consistency was considered from acceptable (for f-JSPE) to strong (for f-TAS20) as demonstrated by GLB and wvalues. A 3-factor structure was determined for both f-JSPE and f-TAS20 scales, as illustrated by the values of goodnessof-fit indices (Table 1).

\section{Scores analysis}

As shown in Table 2, f-CDRISC was significantly best-scored by male residents (low effect size). A significant difference in resilience (low effect size) was observed between the residents of the different years of formation. However, our analysis indicated that such a difference originated more likely from an interaction between gender and year of formation. Gender-related or curriculum-related differences for f-JSPE or f-TAS20 scores were not significant.

\section{Multiple linear regression analysis}

Resilience and empathy were positively correlated, $\mathrm{r}_{(135)}=.36$, $\mathrm{p}<.001$. Negative correlations were observed between alexithymia and resilience, $\mathrm{r}_{(135)}=-.40, \mathrm{p}<.001$, and between alexithymia and empathy, $\mathrm{r}_{(135)}=-.38, \mathrm{p}<.001$. A regression model describing the contribution of the different variables to the resilience was elaborated. It was supported by a significant regression equation, $\mathrm{R}_{\text {adjusted }}^{2}=.27, \mathrm{~F}_{(4,132)}=13.39, \mathrm{p}<.001$, Durbin-Watson coefficient $=1.625$. The resilience was positively predicted by empathy, $\beta=.255, \mathrm{t}_{(132)}=3.19, \mathrm{p}=.002$, and by year of formation, $\beta=.157, \mathrm{t}_{(132)}=2.12, \mathrm{p}=.036$. Meanwhile, gender (female $<$ male, $\beta=-.231, \mathrm{t}_{(132)}=-3.14, \mathrm{p}=.002$ ) and alexithymia, $\beta=-.284, \mathrm{t}_{(132)}=-3.57, \mathrm{p}<.001$, corresponded to negative predicting factors. Alexithymia negatively influenced empathy, $\beta=-.270, \mathrm{t}_{(132)}=-3.21, \mathrm{p}=.002$. Neither alexithymia nor empathy was affected by gender or by year of formation. This model was validated by CFA as demonstrated by the goodness-of-fit indices, $\chi^{2}(5, \mathrm{~N}=137) / \mathrm{df}=.55, \mathrm{GFI}=$ $.99, \mathrm{AGFI}=.98, \mathrm{sRMR}=.042, \mathrm{RMSEA}<.001, \mathrm{p}($ close $)=.846$.

\section{Cluster analysis}

Different convergent solutions resulting from CA were observed. However, ANOVA shows that the differences produced by 3 - and 4-cluster models were not significant (data not shown). For this reason, the 2-cluster model was 
Table 1. Determination of the psychometric properties of empathy and alexithymia scales

AGFI: Adjusted Goodness-of-Fit Index; AIC: anti-image coefficient; CFI: Confirmatory Fit Index; X2/df: normed X2; df: degree of freedom; GFI: Goodness-of-Fit Index; GLB: Greatest Lower Bound

\begin{tabular}{|c|c|c|c|c|c|c|c|c|c|c|c|c|}
\hline \multirow{2}{*}{ Scale } & \multirow{2}{*}{$\mathrm{KMO}$} & \multirow{2}{*}{ Bartlett's test } & \multirow{2}{*}{$\mathrm{AIC}$ range } & \multirow{2}{*}{$\begin{array}{c}\text { Mean } \\
\text { rIS (135) (SD) } \\
{[95 \% \mathrm{Cl}]}\end{array}$} & \multicolumn{6}{|c|}{ Confirmatory analysis } & \multicolumn{2}{|c|}{$\begin{array}{l}\text { Indicators of internal } \\
\text { consistency }\end{array}$} \\
\hline & & & & & $\chi^{2} / \mathrm{df}$ & sRMR & GFI & AGFI & RMSEA & CFI & GLB & $\omega[95 \% \mathrm{Cl}]$ \\
\hline f-JSPE & 0.79 & $\begin{aligned} \chi^{2}(190, N & =137)=598.8 \\
p & <0.001\end{aligned}$ & $0.608-0.872$ & $\begin{array}{l}0.29(0.15) \\
{[0.22-0.36]}\end{array}$ & 1.32 & 0.07 & 0.87 & 0.84 & 0.047 & 0.88 & 0.87 & $0.70[0.67-0.74]$ \\
\hline f-TAS20 & 0.814 & 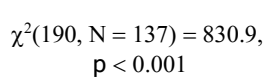 & $0.610-0.911$ & $\begin{array}{l}0.42(0.16) \\
{[0.34-0.50]}\end{array}$ & 1.34 & 0.07 & 0.87 & 0.83 & 0.05 & 0.92 & 0.91 & $0.84[0.81-0.88]$ \\
\hline
\end{tabular}

coefficient; rIS: item-score correlation coefficient; KMO: Kaiser-Meyer-Olkin coefficient; $\omega$ : McDonald's $\omega$ coefficient; RMSEA: Root Mean Square Error of Approximation; sRMR: standardized Root Mean Square of Residuals; [95\% CI]: 95\% confidence interval.

considered as the most reliable solution. This was validated by DA. The cluster effective calculated by DA were found to be identical to those determined by CA. A very strong correlation between the allocations determined by CA and by DA was observed, $\mathrm{r}_{(135)}=.98, \mathrm{p}<.001$.

The gender repartition determined for each cluster was similar (Table 3). By contrast, between-cluster differences calculated for resilience, empathy, and alexithymia were significant. The residents of cluster 1 were more resilient and more empathetic than those of cluster 2 (strong effect size). The residents allocated to cluster 2 exhibited a higher alexithymia profile (strong effect size). The between-cluster difference was also observed when the year of formation was considered as comparison criterion. In particular, residents from 3rd year were more abundant in cluster 1 , whereas cluster 2 was mainly constituted by 1 st and 2 nd-year residents.

\section{Discussion}

The objective of the present study consisted in a better understanding of the characteristics of resilience of medical students. Our work was devoted to the measure of resilience, to the characterisation of some resilience predicting factors and to the analysis of the resilience distribution in a sample of French general practice residents. Two working hypotheses have been tested: i) the resilience is affected by several predicting factors including empathy and alexithymia and ii) the distribution of resilience among the studied sample is heterogeneous.

\section{Characterization of the resilience}

To explore our first working hypothesis, f-JSPE and f-TAS20 scales are used for empathy and alexithymia measurements. These scales have been described as reliable tools in different French-speaking samples. ${ }^{44,45,53-55}$ However, a psychometric scale needs de novo validation when study conditions are changed. ${ }^{52}$ Our work confirms that f-JSPE and f-TAS20 correspond to reliable tools for empathy and alexithymia measurements in French medical residents.

The average score of alexithymia calculated for French medical residents is similar to those calculated for French asymptomatic adults, ${ }^{45}$ and for German and Japan general populations. ${ }^{56,57}$ There are contradictory results concerning a gender-related difference for alexithymia in the literature. Indeed, previous observations highlight some gender-related differences in German and Jordanian general populations. ${ }^{56,58}$ However, other reports show that alexithymia is unaffected by the gender of French or Japan individuals. ${ }^{45,59,60}$ Our study shows that the gender of French medical residents does not influence their alexithymia trait.

The average score of empathy calculated in the present work is in good agreement with those calculated for medical students ${ }^{61}$ and for French medical practitioners. ${ }^{54,62}$ The fact that empathy level is affected by gender or not, is currently debated. On the one hand, a higher empathy is reported for females in samples of undergraduate students of Portugal and USA ${ }^{63,64}$ On the other hand, North American and Brazilian male residents have higher empathy levels than their female equivalents. ${ }^{65,66}$ The present study does not report any gender-related empathy difference for French medical residents. This suggests that medical formation at Nantes University minimizes or abolishes the empathy difference between male and female medical students during their early training.

The resilience measured for French medical residents is higher than that determined for Chinese, Korean and US general populations. ${ }^{67-69}$ By contrast, it is close to that measured for Australian nurses or Brazilian athletes daily living in stressful conditions $s^{70,71}$ and for Chinese and Turkish earthquake survivors. ${ }^{72,73}$ This indicates that medical formation provides a training environment susceptible to support the resilience of medical students.

The relationships between resilience, empathy, and alexithymia have never been fully described, because of a lack of concomitant measurements. It is shown in the present work that empathy and alexithymia correspond to significant predicting factors of resilience. Indeed, resilience is negatively influenced by alexithymia and positively affected by empathy which is also negatively influenced by alexithymia. A decline of medical students' empathy occurs as students progress in their training. ${ }^{74}$ Our findings suggest that such a decline can be accompanied by the decrease of the students' resilience, thus rendering the students more 
Morice-Ramat et al. Alexithymia, empathy and resilience of medical residents

Table 2. Resilience, empathy and alexithymia of general practice residents

\begin{tabular}{|c|c|c|c|}
\hline Variable & f-CDRISC & f-JSPE & f-TAS20 \\
\hline Overall $(n=137)$ & $3.17(.73)[2.77-3.57]$ & $5.61(.43)[5.44-5.73]$ & $2.38(.54)[2.23-2.58]$ \\
\hline Female $(n=94)$ & $2.79(.70)[2.57-3.01]$ & $5.63(.41)[5.44-5.72]$ & $2.38(.54)[2.28-2.62]$ \\
\hline Male $(n=43)$ & $3.34(.63)$ [3.17 - 3.57] & $5.57(.47)[5.44-5.73]$ & $2.37(.56)[2.17-2.53]$ \\
\hline Gender Comparison (d) & $\mathrm{t}_{(135)}=2.09, \mathrm{p}=.038(.12)$ & $\mathrm{t}_{(135)}=.69, \mathrm{p}=.408$ & $\mathrm{t}_{(135)}=.01, \mathrm{p}=.918$ \\
\hline Year-1 (41) & $3.13(.67)$ [2.92 - 3.34] & $5.57(.49)[5.46-5.71]$ & $2.40(.56)[2.23-2.58]$ \\
\hline Year-2 (53) & $2.79(.69)[2.57-3.00]$ & $5.57(.47)[5.41-5.72]$ & $2.41(.54)[2.24-2.57]$ \\
\hline Year-3 (43) & 3.49 (.63) [3.29 - 3.69] & $5.69(.40)[5.56-5.82]$ & $2.27(.55)[2.09-2.44]$ \\
\hline Between-year Comparison $\left(\eta^{2}\right)$ & $F_{(2,134)}=6.10, p<.001(.18)$ & $\mathrm{F}_{(2,134)}=.60, p=.549$ & $F_{(2,134)}=.47, p=.628$ \\
\hline Gender x Year Comparison & $F_{(1,131)}=3.70, p=.027$ & $F_{(1,131)}=2.25, p=.109$ & $F_{(1,131)}=2.12, p=.124$ \\
\hline
\end{tabular}

Data correspond to average scores (SD) and $95 \%$ confidence interval $([95 \% \mathrm{CI}])$ calculated for the overall sample and different sub-samples. $\mathrm{d}$ and $\mathrm{n}^{2}$ : effect size of differences.

Table 3. Characteristics of the clusters resulting from cluster and discriminant analyses

\begin{tabular}{|c|c|c|c|c|}
\hline Analycic & Characteristics & Cluster 1 & Cluster 2 & test sianificance (d) \\
\hline & $\mathrm{N}$ & 54 & 83 & \\
\hline \multirow{3}{*}{ Cluster analysis } & $\mathrm{f}-\mathrm{CDRISC}$ & $3.58(.62)$ & $2.81(.64)$ & $\mathrm{t}_{(135)}=-6.99, \mathrm{p}<.001(1.22)$ \\
\hline & f-JSPE & $5.91(.31)$ & $5.42(.38)$ & $t_{(135)}=-8.06, p<.001(1.44)$ \\
\hline & f-TAS20 & $1.88(.35)$ & $2.70(.38)$ & $\mathrm{t}_{(135)}=12.91, \mathrm{p}<.001(2.27)$ \\
\hline \multirow{4}{*}{ Discriminant analysis } & $\mathrm{N}$ & 54 & 83 & \\
\hline & f-CDRISC & $3.58(.62)$ & $2.81(.63)$ & $\mathrm{t}_{(135)}=-6.95, \mathrm{p}<.001(1.23)$ \\
\hline & f-JSPE & $5.91(.31)$ & $5.43(.38)$ & $t_{(135)}=-7.82, p<.001(1.40)$ \\
\hline & f-TAS20 & $1.87(.34)$ & $2.70(.38)$ & $\mathrm{t}_{(135)}=13.15, \mathrm{p}<.001(2.33)$ \\
\hline Gender $(\mathrm{F}-\mathrm{M})$ & & $36-18$ & $58-25$ & $\chi^{2}(1, N=137)=.04, p=.84$ \\
\hline \multirow{3}{*}{ Year of formation (\%) } & 1 & $14(25.9)$ & $27(32.5)$ & \multirow{3}{*}{$\chi^{2}(2, N=137)=7.21, p=.03$} \\
\hline & 2 & $16(29.6)$ & $37(44.6)$ & \\
\hline & 3 & $24(44.5)$ & 19 (22.9) & \\
\hline
\end{tabular}

The data correspond to average scores (SD). P value indicates the significance. The effect size is given by Cohen's coefficient (d).

vulnerable to $\mathrm{PBO}$. Apart from training programs suggested for resilience enhancement, ${ }^{75,76}$ education programs devoted to the reinforcement of students' empathy could represent an efficient strategy aiming to support resilience. Also, helping students in the understanding of their own emotions could also figure a protection factor against PBO.

\section{Analysis of the distribution of resilience}

Cluster analysis has been used to describe heterogeneous distributions of empathy, ${ }^{64}$ alexithymia ${ }^{57,77}$ and resilience ${ }^{37}$ among pathological and non-pathological populations. However, these results have been obtained with independent measurements of empathy, alexithymia or resilience. In the present study, empathy, resilience, and alexithymia are concomitantly measured, and cluster analysis considers the three variables simultaneously. Two clusters of residents are identified in very good conditions of confidence. The former is mainly composed of 3rd-year residents with low alexithymia trait and high empathy and resilience. The latter is predominantly constituted by 1 st and 2 nd-year residents with a high alexithymia propensity and low empathy and resilience. This suggests that the medical residency training increases the emotional understanding and the resilience of the residents. Considering normative data, ${ }^{61,69}$ the residents of both clusters exhibit non-pathological levels of empathy and resilience. However, a TAS20 score higher than 2.65 is reported to indicate a strong alexithymia propensity. ${ }^{56}$ Consequently, our work suggests that the residents of the second cluster have a high alexithymic profile. Therefore, this work corroborates Shapiro's comments concerning the promotion of students' alexithymia during preclinical and clinical medical formation. ${ }^{78}$ Predictive determinants of alexithymia during early stages of medical training shall be investigated in future studies.

\section{Limitations}

Although significant datasets support our work, it presents several limitations. It corresponds to a monocentric study (Faculty of Medicine of Nantes). The results are based on a limited number of responses ( $49 \%$ of the population of residents). A selection bias may be present in the survey, as collected responses can originate from students with a positive 
a priori for this study. Furthermore, medical residents are potentially able to identify socially acceptable answers concerning the level of empathy associated with medical practice. Fisher and Katz describe this social desirability-bias on selfreport assessment. ${ }^{79}$ It may be responsible for some overestimated responses and the present survey. The last limitation concerns the design of the study which corresponds to a cross-sectional survey. This prevents the observation of timerelated changes in empathy, resilience, and alexithymia. Consequently, further longitudinal investigations based on larger samples obtained from different medical schools are necessary.

\section{Conclusions}

Our study corresponds to the first concomitant analysis of resilience, empathy and alexithymia traits in a sample of French general practice residents. It is shown that empathy, alexithymia, year of formation and gender are predicting factors of resilience. Our work suggests that it is possible to sustain the resilience of residents by acting on their empathy and alexithymia. Our study shows that residents can be segmented into two subgroups of distinct profiles concerning their empathy and resilience and their alexithymia. Medical training teams should consider these findings to improve their teaching strategies.

\section{Conflict of Interest}

The authors declare that they have no conflict of interest.

\section{References}

1. Salvagioni DAJ, Melanda FN, Mesas AE, González AD, Gabani FL, Andrade SM. Physical, psychological and occupational consequences of job burnout: a systematic review of prospective studies. PLoS One. 2017;12(10):e0185781.

2. Dimsdale JE. Psychological stress and cardiovascular disease. J Am Coll Cardiol.2008;51(13):1237-46.

3. Huerta-Franco MR, Vargas-Luna M, Tienda P, Delgadillo-Holtfort I, Balleza-Ordaz M, Flores-Hernandez C. Effects of occupational stress on the gastrointestinal tract. World J Gastrointest Pathophysiol. 2013;4(4):108-18. 4. Gunnar M, Quevedo K. The neurobiology of stress and development. Annu Rev Psychol. 2007;58:145-73.

5. Shanafelt TD, Boone S, Tan L, Dyrbye LN, Sotile W, Satele D, et al. Burnout and satisfaction with work-life balance among US physicians relative to the general US population. Arch Intern Med. 2012;172(18):1377-85.

6. Shanafelt TD, Hasan O, Dyrbye LN, Sinsky C, Satele D, Sloan J, et al. Changes in burnout and satisfaction with work-life balance in physicians and the general us working population between 2011 and 2014. Mayo Clin Proc. 2015;90(12):1600-13.

7. Norlund S, Reuterwall C, Höög J, Lindahl B, Janlert U, Birgander LS. Burnout, working conditions and gender - results from the northern Sweden MONICA study. BMC Public Health. 2010;10:326-34.

8. Maske UE, Riedel-Heller SG, Seiffert I, Jacobi F, Hapke U. Prevalence and comorbidity of self-reported diagnosis of burnout syndrome in the general population. Psychiatr Prax. 2016;43(1):18-24.

9. van Mol MM, Kompanje EJ, Benoit DD, Bakker J, Nijkamp MD. The prevalence of compassion fatigue and burnout among healthcare professionals in intensive care units: a systematic review. PLoS One. 2015;10(8):e0136955.

10. Kumar S. Burnout and doctors: prevalence, prevention and intervention. Healthcare (Basel). 2016;4(3):37-45.
11. de Paiva LC, Canário ACG, de Paiva China ELC, Gonçalves AK. Burnout syndrome in health-care professionals in a university hospital. Clinics (Sao Paulo). 2017;72(5):305-9.

12. Soler JK, Yaman H, Esteva M, Dobbs F, Asenova RS, Katic M, Ozvacic Z, et al. Burnout in European family doctors: the EGPRN study. Fam Pract. 2008;25(4):245-65.

13. Lee RT, Seo B, Hladkyj S, Lovell BL, Schwartzmann L. Correlates of physician burnout across regions and specialties: a meta-analysis. Hum Resour Health. 2013;11:48-63.

14. Ishak W, Nikravesh R, Lederer S, Perry R, Ogunyemi D, Bernstein C. Burnout in medical students: a systematic review. Clin Teach. 2013;10(4):242-5.

15. Bullock G, Kraft L, Amsden K, Gore W, Prengle B, Wimsatt J, et al. The prevalence and effect of burnout on graduate healthcare students. Can Med Educ J. 2017; 8(3): e90-e108.

16. de Cavalcante Almeida G, de Souza HR, de Almeida PC, de Cavalcante Almeida B, Almeida GH. The prevalence of burnout syndrome in medical students. Arch Clin Psychiatry. 2016;43(1):6-10.

17. Dyrbye LN, Thomas MR, Huntington JL, Lawson KL, Novotny PJ, Sloan JA, et al. Personal life events and medical student burnout: a multicentre study. Acad Med. 2006;81(4):374-84.

18. Galam E, Komly V, Le Tourneur A, Jund J. Burnout among French GPs in training: a cross-sectional study. Br J Gen Pract. 2013; 63(608): e217-24.

19. Rutter M. Annual research review: resilience - clinical implications. J Child Psychol Psychiatry. 2013;54(4):474-87.

20. Jackson D, Firtko A, Edenborough M. Personal resilience as a strategy for surviving and thriving in the face of workplace adversity: a literature review. J Adv Nurs. 2007;60(1):1-9.

21. Hao SW, Hong W, Xu HH, Zhou LL, Xie ZY. Relationship between resilience, stress and burnout among civil servants in Beijing, China: mediating and moderating effect analysis. Personal Individ Differ. 2015;83:65-71.

22. Treglown L, Palaiou K, Zarola A, Furnham A. The dark side of resilience and burnout: a moderation-mediation model. PLoS One. 2016;11(6):e0156279.

23. Zou G, Shen X, Tian X, Liu C, Li G, Kong L, Li P. Correlates of psychological distress, burnout, and resilience among Chinese female nurses. Ind Health. 2016;54(5):389-95.

24. Guo YF, Luo YH, Lam L, Cross W, Plummer V, Zhang JP. Burnout and its association with resilience in nurses: a cross-sectional study. J Clin Nurs. 2017;1-9.

25. Thompson G, McBride RB, Hosford CC, Halaas G. Resilience among medical students: the role of coping style and social support. Teach Learn Med. 2016;28(2):174-82.

26. Houpy JC, Lee WW, Woodruff JN, Pincavage AT. Medical student resilience and stressful clinical events during clinical training. Med Educ Online. 2017;22(1):1320187.

27. Daskalakis NP, Bagot RC, Parker KJ, Vinkers CH, de Kloet ER. The threehit concept of vulnerability and resilience: toward understanding adaptation to early-life adversity outcome. Psychoneuroendocrino 2013;38:1858-73.

28. Taylor GJ. Recent developments in alexithymia theory and research. Can J Psychiatry. 2000;45(2):134-42.

29. Bagby RM, Taylor GJ. Affect dysregulation and alexithymia. In: Taylor GJ, Bagby RM, Parker JD, editors. Disorders of affect regulation: alexithymia in medical and psychiatric illness. Cambridge: Cambridge University Press; 1997.

30. Honkalampi K, Hintikka J, Koivumaa-Honkanen H, Antikainen R, Haatainen K, Viinamaki H. Long-term alexithymic features indicate poor recovery from depression and psychopathology. A six-year follow-up. Psychother Psychosom. 2007;76(5):312-4.

31. Wei H-h, Zhang L-y, Zhou X-d, Wang Y-c, Ren Z-w, H,Chen C-x, et al. A study of correlation between alexithymia and resilience in military personnel. Chin J Behav Med Brain Sci. 2011;20(12):1134-36.

32. Fasihi R, Hassanzadeh R, Mahmoudi G. Correlation between attachment style, alexithymia and resiliency in university students. Int J Sci Basic Appl Res. 2013;2(10):898-902.

33. Halpern J. What is Clinical Empathy? J Gen Intern Med. 2003;18(8):67074. 
34. Park KH, Kim DH, Kim SK, Yi YH, Jeong JH, Chae J, et al. The relationships between empathy, stress and social support among medical students. Int J Med Educ. 2015;6:103-8.

35. Olson K, Kemper KJ, Mahan JD. What factors promote resilience and protect against burnout in first-year pediatric and medicine-pediatric residents? J Evid Based Complementary Altern Med. 2015;20(3):192-8.

36. Mathad MD, Pradhan B, Rajesh SK. Correlates and predictors of resilience among baccalaureate nursing students. J Clin Diagn Res. 2017;11(2):JC05-8.

37. Pietrzak RH, Cook JM. Psychological resilience in older US veterans: results from the national health and resilience in veterans study. Depress anxiety. 2013;30(5):432-43.

38. Doron J, Trouillet R, Maneveau A, Ninot G, Neveu D, Coping profiles, perceived stress and health-related behaviors: a cluster analysis approach. Health Promot Int. 2015; 30(1):88-100.

39. Suriá Martínez R. Profiles of resilience and quality of life in people with acquired disability due to traffic accidents. Gac Sanit. 2015;29(S1):55-9.

40. Chen J, Xu T, Jing J, Chan RC. Alexithymia and emotional regulation: a cluster analytical approach. BMC Psychiatry. 2011; 11(33):1-6.

41. Euler F, Steinlin C, Stadler C. Distinct profiles of reactive and proactive aggression in adolescents: associations with cognitive and affective empathy. Child Adolesc Psychiatry Ment Health. 2017;11:1-14.

42. Bacchi S, Licinio J. Resilience and psychological distress in psychology and medical students. Acad Psychiatry. 2017;41(2):185-8.

43. Guihard G, Deumier L, Alliot-Licht B, Bouton-Kelly L, Michaut C, Quilliot F. Psychometric validation of the French version of the Connor-Davidson Resilience Scale. Encephale. 2018;44(1):40-45.

44. Zenasni F, Boujut E, Buffel du Vaure C, Catu-Pinault A, Tavani JL, Rigal $\mathrm{L}$, et al. Development of a French-language version of the Jefferson Scale of Physician Empathy and association with practice characteristics and burnout in a sample of general practitioners. Int J Person Centered Med. 2012;2(4):759-66.

45. Loas G, Corcos M, Stephan P, Pellet J, Bizouard P, Venisse JL, et al. Factorial structure of the 20 -item Toronto Alexithymia Scale. Confirmatory factorial analyses in nonclinical and clinical samples. J Psychosom Res. 2001;50(5):255-61.

46. Crutzen R, Peters GY. Scale quality: alpha is an inadequate estimate and factor-analytic evidence is needed first of all. Health Psychol Rev. 2017;11(3):242-7.

47. Peters G-JY. The alpha and the omega of scale reliability and validity: why and how to abandon Cronbach's alpha and the route towards more comprehensive assessment of scale quality. EHP. 2014;16(2):56-69.

48. Byrne BM. In: Structural equation modeling with AMOS: basic Concepts, applications, and programming, 2nd edition. Byrne BM, editor. New York: Taylor \& Francis Group, Routledge; 2009.

49. Rosnow RL, Rosenthal R. Computing contrasts, effect sizes, and conternulls on other people's published data: general procedures for research consumers. Psychol Methods. 1996;1:331-40.

50. Lakens D. Calculating and reporting effect sizes to facilitate cumulative science: a practical primer for t-tests and ANOVAs. Front Psychol. 2013; 4:863.

51. Bahr PR, Bielby R, House E. The use of cluster analysis in typological research on community college students. NDIR. 2011;S1:67-81.

52. Costello AB, Osborne JW. Best Practices in exploratory factor analysis: four recommendations for getting the most from your analysis. PARE. 2005;10(7):1-9.

53. Loas G, Fremaux D, Marchand MP. Factorial structure and internal consistency of the French version of the twenty-item Toronto Alexithymia Scale in a group of 183 healthy probands. Encephale. 1995;21(2):117-22.

54. Lamothe M, Boujut E, Zenasni F, Sultan S. To be or not to be empathic: the combined role of empathic concern and perspective taking in understanding burnout in general practice. BMC Fam Pract. 2014;15:15.

55. Loas G, Fremaux D, Otmani O, Verrier A. Prevalence of alexithymia in a general population. Study in 183 "normal" subjects and in 263 students. Ann Med Psychol (Paris). 1995;153(5):355-7.

56. Franz M, Popp K, Schaefer R, Sitte W, Schneider C, Hardt J, et al. Alexithymia in the German general population. Soc Psychiatry Psychiatr Epidemiol. 2008;43(1):54-62

57. Ueno M, Maeda M, Komaki G. Different subgroups of high-scorers on the TAS-20 based on the big five personality traits. Personal Individ Differ.
2014;68:71-6.

58. Hamaideh SH. Alexithymia among Jordanian university students: its prevalence and correlates with depression, anxiety, stress, and demographics. Perspect Psychiatr Care. 2018;54(2):274-280.

59. Zhu X, Yi J, Yao S, Ryder AG, Taylor GJ, Bagby RM. Cross-cultural validation of a Chinese translation of the 20-item Toronto Alexithymia Scale. Compr Psychiatry. 2007;48(5):489-96.

60. Ling Y, Zeng Y, Yuan H, Zhong M. Cross-cultural validation of the 20item Toronto Alexithymia Scale in Chinese adolescents. J Psychiatr Ment Health Nurs. 2016;23(3-4):179-87.

61. Hojat M, Gonnella JS. Eleven years of data on the Jefferson Scale of Empathy-Medical Student version (JSE-S): proxy norm data and tentative cut off scores. Med Princ Pract. 2015;24(4):344-50.

62. Lelorain S, Sultan S, Zenasni F, Catu-Pinault A, Jaury P, Boujut E, et al. Empathic concern and professional characteristics associated with clinical empathy in French general practitioners. Eur J Gen Pract. 2013;19(1):23-8. 63. Hojat M, Gonnella JS, Mangione S, Nasca TJ, Veloski JJ, Erdmann JB, et al. Empathy in medical students as related to academic performance, clinical competence and gender. Med Educ. 2002;36(6):522-7.

64. Duarte Ferreira MI, Barata Raposo ML, Fonseca da Silva Farinha Rodriguès PJ, Castelo Branco M. Measuring empathy in medical students, gender differences and level of medical education: an identification of a taxonomy of students. Inv Ed Med. 2016;5(20):253-60.

65. Moralle MR, Preston JS, Chen L, Berberian WS. An exploratory study of empathy in resident physicians at an urban medical center. IJCS. 2016;9(2):526-33

66. Santos MA, Grosseman S, Morelli TC, Giuliano IC, Erdmann TR. Empathy differences by gender and specialty preference in medical students: a study in Brazil. Int J Med Educ. 2016;7:149-53.

67. Connor KM, Davidson JR. Development of a new resilience scale: the Connor-Davidson Resilience Scale (CD-RISC). Depress Anxiety. 2003;18(2):76-82.

68. Jung YE, Min JA, Shin AY, Han SY, Lee KU, Kim TS, et al. The Korean version of the Connor-Davidson Resilience Scale: an extended validation. Stress Health. 2012;28(4):319-26.

69. Ni MY, Li TK, Yu NX, Pang H, Chan BH, Leung GM, et al. Normative data and psychometric properties of the Connor-Davidson Resilience Scale (CD-RISC) and the abbreviated version (CD-RISC2) among the general population in Hong Kong. Qual Life Res. 2016;25(1):111-6.

70. Gillespie BM, Chaboyer W, Wallis M. The influence of personal characteristics on the resilience of operating room nurses: a predictor study. Int J Nurs Stud. 2009;46(7):968-76.

71. Belem IC, Caruzzo NM, Andrade do Nascimento Junior JR, Lopes Vieira JL Vieira LF. Impact of coping strategies on resilience of elite beach volleyball athletes. Rev. Bras. Cineantropom. Desempenho Hum. 2014;16(4):447-55. 72. Karairmak Ö. Establishing the psychometric qualities of the Connor-Davidson Resilience Scale (CD-RISC) using exploratory and confirmatory factor analysis in a trauma survivor sample. Psychiatr Res.2010; 179:350-6. 73. Yu XN, Lau JT, Mak WW, Zhang J, Lui WW, Zhang J. Factor structure and psychometric properties of the Connor-Davidson Resilience Scale among Chinese adolescents. Compr Psychiatry. 2011;52(2):218-24.

74. Neumann M, Edelhäuser F, Tauschel D, Fischer MR, Wirtz M, Woopen $\mathrm{C}$, et al. Empathy decline and its reasons: a systematic review of studies with medical students and residents. Acad Med. 2011;86(8):996-1009.

75. Farquhar J, Kamei R, Vidyarthi A. Strategies for enhancing medical student resilience: student and faculty member perspectives. Int J Med Educ. 2018;9:1-6.

76. Dyrbye LN, Shanafelt TD, Werner L, Sood A, Satele D, Wolanskyj AP. The impact of a required longitudinal stress management and resilience training course for first-year medical students. J Gen Intern Med. 2017; 32(12): 1309-14.

77. Porcelli P, Guidi J, Sirri L, Grandi S, Grassi L, Ottolini F, et al. Alexithymia in the medically ill. Analysis of 1190 patients in gastroenterology, cardiology, oncology and dermatology. Gen Hosp Psychiatry. 2013;35(5):521-7.

78. Shapiro J. Does medical education promote professional alexithymia? A call for attending to the emotions of patients and self in medical training. Acad Med. 2011;86(3):326-32.

79. Fisher RJ, Katz JE. Social-desirability bias and the validity of self-reported values. Psychol Market. 2000;17(2):105-20 